\title{
So far where we Stand in the Recruitment and Selection Studies? A Review Study based on earlier Studies
}

\author{
Ghulam Nabi (Corresponding author) \\ School of Public Affairs \\ University of Science and Technology of China
}

Email: E-mail: ghulam@mail.ustc.edu.cn, gnabisk@yahoo.com

\author{
Song Wei \\ PhD, Professor \& Dean \\ School of Public Affairs \\ University of Science and Technology of China
}

\author{
Mohammad Waqas Raja, Shuliang Zhao, Bilal Ahmed \\ PhD Students, School of Public Affairs \\ University of Science and Technology of China
}

Doi:10.5296/ ijhrs.v5i2.7606 URL: http://dx.doi.org/10.5296/ ijhrs.v5i2.7606

\begin{abstract}
Since the modern human civilization has become known, the struggle for growth and survival has remained a central focus of all times and it is inevitable to gain this without competitive and well balanced workforce. This lead the studies focus on human resource which has been identified as key resource for organizations, due to which the recruitment and selection become the basic activity for effective selection apart from any ethical, social and legal issues influence. A vast amount of research studies have been conducted in the field of recruitment and selection from various perspectives, due to which it has become difficult to contemplate and comment on its reasonability. This review study has analyzed the different perspectives of the recruitment and selection that has been much focused in earlier studies with a focus on a sole objective of this study, to understand how future studies may be focused to address the issue of generalization and conduct future studies in the field of recruitment and selection.
\end{abstract}

Keywords: Procedural justice, fairness, gender equality, Recruitment, Selection, organizational politics, face validity 


\section{Introduction}

The present review study on the recruitment and selection focuses on the earlier studies on different aspects of the recruitment and selection of employees in the public sector organizations particularly. The main emphasizes have been paid to address the phenomena of recruitment and selection research contributions for the analysis to understand how much is known so far about this most pivotal and primary function of human resource management which is an integral part of almost all institutions regardless of private or public sector. It has become common inferences of the researches in the field of human resource management, that recruitment and selection function is actually the matter of survival or failure of an organization (Compton, 2009 \& Canton, 2004). Long in history of human civilization, the right person on the right job had always been the matter of concerns for the public and private officials to run their affairs in smooth way. It is being one of such a function of human resource management that counts huge value in the context of public sector organizations, because after the selection of an employee, the selection employees' remains with these organizations till their retirement age under the different capacities. In fact all the organizational resources can be on stake if there is a wrong selection for the key positions specifically. The one of a main positive aspect of this research is that it analyzes the issue by building a forward leading approach to reach at some reasonable conclusions of making substantial contributions in the field of recruitment and selection, particularly in the public sector institutions controlled by the government. Researches contributions have been classified according to the various areas for an objective analysis and simplicity of understanding. A rigorous care has been adopted to focus only on the relevant literature regarding the recruitment and selection of employees in the public sector organizations particularly, because we believe that if the public sector employees are effective and competent in performing their jobs effectively will have macro level impact on the economy.

It is a known fact that the recruitment and selection are interrelated and interdependent on each other, therefore, keeping in view it has been noted that there almost negligible attention given to conduct related review studies that addresses comprehensively both the key functions of the organization because any study that address on one function may have a different interpretation if analyzed from the context of other. Furthermore, based on the noted observations of the studies in this field, enormous studies have been found focusing in the recruitment and selection differently. Most studies have been conducted in developed or English speaking countries, which has made it more difficult to understand relevant are the findings, which have different socioeconomic and political scenario to generalize for the lesser developed or non English speaking countries. Another aspect is that there is lack of review studies that analyzes the gender phenomena of imbalance selection in the organizations, which made this research review more significant to conduct. Therefore, this study has narrowed down its overall focus on the all possible dimensions that earlier researches mostly from 2000 to onward have been focusing regarding the recruitment and selection of the employees. This leads us to reach at a specific objective to understand the way future studies can be directed to grasp a comprehensive picture to know more about the recruitment and selection of employee, which doubtlessly has higher need to make a 
significant contribution in the existing body of related literature, especially keeping in view the public sector institutions controlled by the respective governments in the developing or non English speaking countries.

\section{Fairness and Procedural Justice Issue in the recruitment and selection}

Cropanzana et al, (2007) observed that the first interaction between an applicant and organization actually happens at the recruitment and selection stage, because here the applicants get perception about fairness of the selection of employees, which has long lasting effects on employee behavior even after joining organization as an employee. Organizations having higher procedural fairness can get a large pool of applications that helps in making effective selection (Harris, 2000). Gilliland \& Steiner, (1999) identified that injustice in selection sometimes may cause economic issues to organizations because if top performers didn't apply or even if the number are very few, there are a strong chances that the right one may be among them. Harris, (2000) identified that formulation of a procedural justice based selection mechanism has been one of a real dilemma for the organizations. Gilliland, (1993) has made one of a most important contribution by identifying 10 procedural justices based principles to maintain the fairness of a selection system. Cropanzana, (2007) observed that the procedural justice based selection mechanism can enhance the trust level land bring commitment of an organizational employees. In the public institutions it has become common that their recruitment and selection practices are facing the issue of unfair practices and in USA \& UK nepotism and cronyism is the main acquisition upon these public institutions (Taylor, 2006). Gilliland, (1993) suggested that fairness reaction by the applicants may have a relationship with the legal action against the recruiter.

Hausknecht et at, (2004) found that applicants who have positive perception about the organizational selection procedures view organization more positive way and also they strongly recommend others for such organizations. In a research literature on perceptions of applicants, there are two basic urges to conduct research, one is that of fairness of recruitment and selection process and the other one is selection method an important influencer on the applicants' attraction towards an organization (Gilliand, 1993). Chan et al, (1998) found that the fairness of the applicants' perceptions towards fairness of the selection procedures and its relevancy with job requirements are being influenced by the applicants' performance which they perceive. Outcome of a selection procedure directly affects the perceptions of the applicants as those applicants perception that had expectation of being hired were positively related to fairness and those who were not selected had negative fairness perception (Gilliand, 1994).

Applicants perception of fairness about the selection procedures may be influenced because of the already familiarity of an applicant about some specific selection procedures (Truxillo et al, 2004). The major cause that influences the perception is the favorable outcome of a recruitment and selection process but at the same time in some cases an applicant does not see his performance well before any feedback, as it is not enough to relate outcome with the perception only (Ryan \& Polyhart, 2000). In many situations it is happening that applicants are being influenced by their experiences from already appeared selection procedures and 
also how they perform in the present situation (chan et al, 1997). Vianen et al, (2004) highlighed that in making selection of an employee the situational judgment test has higher rating as compare to the cognitive ability and personality test. Sonja Schinkel et al, (2004) found that feedback has relevance with the procedural fairness but the problem is that how to give feedback of their performance in case of rejection decision which is generally assumed not good for the organization. Gilliland, (1993 \& 2001) have reported that fairness in the selection procedures can be enhanced by conveying true and accurate information to the candidates. Vianen et al, (2004) that it is highly significant for the organizational internal selection department or external agency to focus on quality feedback to remain attractive among the potential applicants. Pre test perception regarding any selection procedure of an applicant has direct impact on ones performance and is highly significant because it has affects on the post test reaction of an applicant (Chan et al, 1998). Public policy about the selection procedures play a very significant role and it has been suggested if the organization wants to make any effective public policy they have to focus on the procedural justice as an important element of it to impose its law obedience (Gau, 2011).

\section{Meritocracy, Organizational and State Politics in selection of a critical factor}

Vigoda, (2000) has identified that organizational politics has affecting negatively the employees reaction and has found that in the public sector organizations the employee prefer silence by showing negligent behavior if they feel politics around them, as they don't want to quite the job. Lee \& Renzetti (1990) have declared that studies on the recruitment \& selection are actually talking a very sensitive area to be analyzed with some ethical \& legal consequences. Taylor (2006) identified that research investigation in managerial practices which clashes with the common social norms and exposure of asymmetrical power relation can be threatening. Schneider (1992) has observed that in 1945 post era Brazil was one of an effective state led industrialization but due to serious issues in the bureaucracy and political involvement especially in the field of recruitment and selection this couldn't be maintained. Taylor, (2006) suggested that the researchers should focus on the political and ethical aspects of the recruitment and selection practices rather than looking into the economic and technical aspects.

Krause et al., (2006) noted that citizen elect their members in a democratic set up to work for them but the struggle starts once these members interact with the bureaucracy of the agency or organization to implement their policies and on the other hand the bureaucracy tries to maintain their independence, in such cases the politicians select their non elected supporters in the public offices that generate multiple agency issues. Suleiman, (2003) has highlighted that in many countries it has been observed that due to political appointees, the organizational performance and morale has been negatively hit, that has caused a hurdle in the way of effective recruitment and selection. Many countries are hiring top position or executive are being selected with the approval by the top politicians and rest are being selected through organizational internal prevailing mechanism (Krause, 2006).

Lew, (2007) observed that it is evident from the literature that political appointments to have more political control hurt the organizational performance and found that due to longer 
experience in the programs the bureau chief performance was higher than those chiefs who have been politically appointed. Huber \& McCarty (2004) has identified that the bureaucrats sometimes may not listen to the politicians and in such cases these politicians will punish them in by all means. Researchers have elucidated that the basic objective of the career merit system was to enhance the capability \& capacity of government to perform effectively because of having relevant knowledge, skills and professional background (Kaufman 1965; Simon, Thompson, and Smithburg [1950] 1991). Vigoda (2003) has claimed that most of the research studies on organizational politics have been perceived negatively while as (Drory, 2010) has identified that traditionally it has been seen as evil.

Gajduschek (2007) have claimed on the basis of his analysis about the main features regarding merit based system in which he found that the merit system enables the avoidance of political influence which is unfair and it fosters the significance of the regulations, moreover he found that there is a significance consensus among various researchers that the recruitment and selection must be according to the merit apart from other factors. Bossaert \& Demke (2003) elaborated that the countries that were previously under communism have developed and implemented the merit based system which is according to the legal regulations that actually are in contrary to the communism era of personnel policy. Gajduschek (2007) have referred the unanimous stand of the earlier researchers that political control over the various personnel activities related to managers recruitment and selection, promotion and their removals from their designated positions enables positions to take the advantage of the loopholes in the law by keeping a strict political control to make political selections on different top positions of the government ministries. Vigoda-gadot and kapun (2005) have conducted study based on public \& private sector employees in which they found that public sector organizations are more politically involved as compare to the private sector organizations. Vigoda-gadot (2007) has identified that in past communism the communist system stood unreliable and the new cabinets changed the top level positions with their loyal ones, which remained a problem as new cabinets replaced them by their politically loyal ones which became a major issue that is continue even after the government changes. Sealy (2010) have found the merit for women has become a challenge issue due to the promotion of social capital which is considered as a political behavior over human capital that focuses on the knowledge, skills, abilities and the other experiences.

Sealy (2010) has argued that the prevalence of the merit based career progression for women has become complicated due to lack of women members in the top executive positions in the organizational leadership and women that are being selected through quota system in public organizations raises the question of meritocracy. People who have been selected on merit claims that they have been selected on merit and they know what actually merit is by shaping a group, this has become a major hurdle for promoting the real meritocracy (McMamee et al., 2004). Sealy et al., (2009) have pointed out that on the top executive positions of the corporations, we observe very few female managers which was also seen by (Nabi et al., 2014) regarding female stereotypes in the top executive positions in the governments that female in the federal cabinets for the governments were found very negligible. Merit is considered a principal in which only those people are rewarded who deserve which is 
unbiased (Son Hing et al., 2002) but the question arises that why females on top positions are underrepresented in both public and private sector organizations. It has been argued that there may be various issues in assessing the merit in test evaluations and analyzing the comparative performance that may favor the white males (Song hing et al., 2002). Sealy (2010) have mentioned that the violation of the meritocracy can also cause the discrimination but at the same time women are believed in making choices to maintain work life balance instead of the struggle to reach on the top, which (Hing et al.,2002) found that people believes in meritocracy and they abstain raising their objections when they see that the discrimination at workplace which is associated with the adherence of the merit. Krinitcyna and menshikora (2015) found in her study conducted in Russian context that there is a huge discrimination based on employment, transfer and career development with females. Sealy (2010) have mentioned that the violation of the meritocracy can also cause the discrimination but at the same time women are believed in making choices to maintain work life balance instead of the struggle to reach on the top, which (Hing et al.,2002) found that people believes in meritocracy and they abstain raising their objections when they see that the discrimination at workplace which is associated with the adherence of the merit.

Brink et al., (2006) have mentioned that in order to be selected for a professorship in the academic sphere, the social capital is one of a factor other than talent \& merit that also influences the decision for selection. Bagilhole \& Goode (2001) have concluded that various networks that are dominated by the male networks favor men more as compare to the females, which causes problems in adopting them. Snyder and weingast (2000) argued that the personnel selection system is not always politicized, however some personnel selection agencies do act of the hiring and firing according to the will of the political actors which he referred "at will" system of hiring and firing of employees. It Tucker \& pounder (2010) referred regarding personnel administration that most of the studies about personnel administration has been taken place in the English speaking countries, which raises the various cross cultural related concerns due to its narrowness from this perspective. Tucker \& pounder (2010) have argued that personnel administration policies are being influenced by the globally required knowledge by the business forces and agreements of collective bargaining between employees unions and agencies. Breaugh et al., (2008) figured out that recruiter effect has attracted much of the researchers' attention but it has been noted that minimum was being made about the other factors that may have indirect interaction with the effective recruitment strategies. Although a vast amount of research has been made in the recruitment and selection but their major focus has remained on the methods and realistic job preview (Breaugh, 20008 saks, 2005) which is a genuine concern as the focus on the way of structural factors other than recruitment and selection methods especially the recruitment and selection policy, bureaucracy and politicians influence over the merit based selection.

\section{Gender inequality, Transparency Issues and Selection Mechanism}

Kusterer (2014) has made a study on a women empowerment project to unfold the discourse which is concerned about women on top positions of corporate sector which he attributed with the government change. In Scandinavian countries the gender equality policy has remained central policy but still there is male dominancy in the public sector institutions 
which has become a paradoxical phenomenon (Tigen, 2002). Generally there are two concepts regarding the gender equality promotion, one is justice argument and according to the (Phillps 1995 \& Tigen, 2000) this argument supports for roughly equal distribution of power and influence between gender and the other one is resource argument, that pleads gender equality is being dealt according to the benefit point of view that an organizations may get after hiring an employee (Phillips, 1995). Brink (2006) found in his study that there is a vivid gap between the male and female mobility towards the upward in employment hierarchy. Van Balen, (2001) actually there are multiple reasons of not allowing the women in appointments and he has found that one of the issue is lack of the transparency in making the female selection while as (Lews, 2002) has identified that male dominancy in the selection committees which influence the female selection is the major issue.

Dory (2010) has mentioned that many issues that are causing due to ambiguities are causing due to lack of clarity in the standardized procedures which makes those who are in the power strong to make involvement that may affect the process. Lee \& Renzetti (1990) declared that studies on the recruitment $\&$ selection are actually talking a very sensitive area to be analyzed with some ethical \& legal consequences, while as according to the (Taylor, 2006) the research investigation in managerial practices which clashes with the common social norms and exposure of asymmetrical power relation can be threatening. It has been noted on the basis of earlier studies that transparency has remained a top issue in the gender selection for bringing gender equality, especially when the authorities practices such selection evaluation process which is confidential by nature because in an open selection evaluation system the females have more chances to be selected (Husu, 2000 and Ziegler 2001). Brink et al., (2010) the lack of transparency in the selection can cause more favour to a specific candidate because in flexible criteria's in the selection evaluation, the panel members may change their opinion that can be due to power game as well.

\section{Gender Equality and Face Validity in Selection Procedures as an challenging issue}

In open competition the women perform better but due to the lack of transparency in selection procedures it has influenced the gender selection (Van Balen, 2001; Broun's 2000). Husu (2000) has found in his study that in the open competition the women were selected twice as compare to the males. It has been identified that there are specific networks in the organizations that play a crucial role in career opportunities and it is difficult for the women to make an access with these networks (Van Balen, 2001; Harris, 2002). Khurana (2002) has mentioned in his study that it is difficult for a women to be selected if the panel or committee is being male dominated. Brink et al (2006) elaborated that the gender discrimination can be avoided if organizations would adopt open selections system i.e., (advertising the post in the journals or newspapers) as compare to the closed or semi open selection procedures. Liu (2013) argued in his study regarding the women in top, that women managers have full capacity to handle the issue or concerns of stakeholders arising due to the changing environment acceptable to all, however he stressed the need that they need institutional or systematic support to advance in their career. However (Brink at. al, 2006) has found that women can have more probability to be appointed if the selection committee consists of a significant number of women members. Linghag (2009) reported that in many Swedish 
researches it has been found that the traditional gender norm have been kept preserved and according to Kusterer (2014) if you want to maintain gender equality on the top then this traditional phenomena must be checked to realize the gender equality objective.

Górecki \& Kukołowicz (2014) found that the mandatory quotas for bringing more women have shown a considerable increase of the women but at the same time this has shown a fast down fall in their performance regardless of their past background of experiences. Brink et al.,(2011) highlighted that although the academic excellence is considered neutral, while as considering the gender about the merit but in Netherland based study he found that this doesn't hold true and actually the prevailing practices in academic practices in academic excellence are supportive for the male dominancy. Gender bias is not only due to male dominancy but also the females have more stereotypical perception towards male applicants and (Cole et al., 2004) found in his study on the recruiter evaluation process of the candidates that during the selection process the male recruiter views gender qualification \& experiences same, while as female recruiter showed tilt towards male applicants. Ben chop and Broun's, (2003) noted that the selection board has not selected women because of the similar to me reason in spite of all this that they had same qualification and were on merit too. Steipreis et al., (1999) reported that women and men both selected the male candidate by ignoring the fact that both had equal and same level of qualification, which implies females have gender bias towards male as well. Diversity due to gender on the top positions brings various advantages in the way of making decisions in a specific situation because both male and female way of assessment to handle a specific situation is different that leads in the benefit of organization. (Weidekamm and Willer, 2012).

Doherty (2006) observed in a study that women are showing a reluctant behavior in pursuing their advancement of career and they prefer a work that maintains work life balance. Liu (2013) mentioned in his study regarding the women in top, that women managers have full capacity to handle the issue or concerns of stakeholders arising due to the changing environment acceptable to all, however he stressed the need that they need institutional or systematic support to advance in their career. Marshall \& Ramsey, (1999) have stressed that by empowering the female there will be positive effect on the policies and the way actions are being taking place, however if we empower a single women in a dominant environment, that will not bring any change in the context of using force but a real change will occurs when the gender empowerment takes place in groups. The measurement of the gender equality is a technical and political issue, especially when it comes about the measurements of the gender equality progress, which always depends on the priorities of the decision makers (Moser, 2007). It has been found that the female in the real power as the chief of government has not brought any positive change in gender equality in their cabinets (Nabi \& Song., 2014).

Syed et.al.,(2009) have argued that the important factor of gender equality is their historic culture, socio political and economic setup that may have impact on gender equality in their employment pattern Linghag (2009) reported that in many Swedish researches it has been found that the traditional gender norm have been kept preserved and according to Kusterer (2014) if you want to maintain gender equality on the top then this traditional phenomena must be checked to realize the gender equality objective. Górecki \& Kukołowicz (2014) have 
found that the mandatory quotas for bringing more women have shown a considerable increase of the women but at the same time this has shown a fast down fall in their performance regardless of their past background of experiences. Gneezy et al.(2008) found in Indian context that females are not participating in risky and competitive behaviors as like male which according to (Górecki \& Kukołowicz, 2014) is untrue as he found that women do take part equally in all sorts of risky and competitive behaviors and it has nothing to do with the inherent genetics. Brink et al., (2011) argued that although the academic excellence is considered neutral, while as considering the gender about the merit but in Netherland based study he found that this doesn't hold true and actually the prevailing practices in academic practices in academic excellence are supportive for the male dominancy. Syed (2009) has found in a study based on Turkey and Pakistan that shariah and secularism are causing major hurdle in promotion gender equality agendas in these Ben chop and Broun's, (2003) has noted that the selection board has not selected women because of the similar to me reason in spite of all this that they had same qualification and were on merit too. Steipreis et al., (1999) has reported that women and men both selected the male candidate by ignoring the fact that both had equal and same level of qualification, which implies females have gender bias towards male as well.

Face validity has been the facility in terms of the degree to which the individual items of a test are being perceived by its users about its relevancy of predicting assessment objectives (Anastasi, 1988). Gaber and Gaber (2010) Face validity of a research as the basic common sense which one derives after reading the conclusions of the research and making a judgment that whether this research makes a sense or not, in the context of the selection of the employees for the government it is necessary to see the same from the applicant perspective. Kerlinger, F. (1986) has described that validity is generally knows as the question mark of that whether the asked question of a rating assessment does measures the accurate answer. Various researchers have mentioned that the face validity is not important because it give the results that are based on observation and cannot be verified through any assessment procedures (Newfields, T. 2002).

Gaber and Gaber (2010) have discussed that there is increasing trend of looking the research findings or projects with its face validity a qualitative assessment aspect because this enable the people involved in the planning to understand the feasibility of their findings and directly the way it will be experienced by the community perspective. Gaber and Gaber (2010) have identified a very important learning lesson that for the planners of various projects can use face validity to find any such area which they have missed during their analysis of their projects and due to this they will be able to increase the value of their plan by bringing timely and needed improvements. Nabi et al., (2014) observed that this is with special significance with reference to the face validity of the selection procedures as face validity can be the first step to take the case into court by any applicant or any other party. In the contemporary world organizations has to see the selection function of the organization strategically to maintain or gain competitive advantage (Polychart, 2011). Schmidt \& Zimmerman (2004) proved through a meta-analysis that four unstructured interviews reliability are equal to a single structure interview. The selection authorities are using apparently structured interview through a panel 
but practice wise that is unstructured when it is being conducted to select a right person on right job (Nabi et al., 2014). Livens et. al.,(2005) noted that in order to achieve the maximal performance the test as predictor must be matched with the job related criteria. Hardesty \& Bearden (2004) have defined face validity in terms of its degree of measurement intention about a rating item and mentioned that face validity is very important to have the valid operationalization of the construct.

\section{Conclusion}

After a careful analysis of the selected literature on recruitment and selection, it is hard to reach at a one conclusion because of its multi polarity nature and size of the organizations that are being run and managed by people having various types of knowledge, skill and relevant levels of expertise. This may be the reason that still it is complicated to comment on the reasonability and suitability of the studies conducted so far in this field. The main issue of the institutional heads and shareholders is their focus on enhancing the financial or market worth of their stock by exploiting certain general and public ethics that generates the discrimination in hiring practices. While as in the public sector that is controlled by the government, studies have identified that the most serious challenge for public institutions having the right blood and talent is the violation of meritocracy. This stresses that the authorities must select and retain the right people on right job without any regards or influence from any side. This further has been become a major issue because due to non compliance of the meritocracy, it directly influences the gender balanced selection that is crucial for brining of only component of social diversity in all sorts of public or private institutions. The most emergent threat to promoting the merit based selection in the public institutions particularly seems interpretation of the meritocracy, because presently the logic of social capital poses a greater challenge for it's the justification to give priority on human capital, which in true essence is the logic of meritocracy. Earlier the main issue for the right selection in public sector institutions was the issue of transparency in the selection procedures that caused the possibility of intervention by the different inside and outside people or entities in power and authority to make their desired selection of the individuals. So generally we can categorize that studies have proved that, so far almost all the selection procedures in different public and private sector institutions have not been able to stop the discrimination based on the gender particularly. Regarding the issue of ethnic, regional or religion based exploitation during the selection of the respective individuals; the studies are exhibiting mixed results that cannot be generalized across the different cultures or at a larger setting.

There are enormous studies that had focused on the external and internal forces influencing the selection procedures, among which the most significant has been the issue of political influences both internally and externally in the organization. Some of the significant studies were made by notable researchers in late $20^{\text {th }}$ century that focused on the justice issues in the recruitment and selection. They identified that organizational and procedural justice are mainly two key issues that can make the recruitment and selection activities meaningful for the organizations to boost their performance because procedural justice particularly has a significant impact on the fairness of the selection procedures. Regarding the gender imbalances in the employment pattern, the researcher have identified similar scenario like 
social capital instead of human capital preference, here observed that the drastic lack of female representation in the employment pattern in public and private sector institutions are being claimed due to the female stereotypes of the masculine strength. Although studies have proven that by all aspect the social diversity is highly significant for the better and productive performance of an organization. Various studies have stressed that the gender equality scenario can only be improved once the change commences from the top structure of the policy or legislation making institutions because only this can overcome the issue of powerful male dominated networks that hamper the women progress in their career for taking higher and powerful positions. There are few studies that have studied the recruitment and selection from the social, religion and regional scenario and have found that in some regions the religion and the social setup does influence the selection of a female in the organizations but still this needs to be examined further to validates this finding.

Finally, the most important aspect of these studies is that majority of the researches have adopted a piece meal approach in making their conclusions or drawing the findings their focus had remained in taking sample from those who have not experienced the screening tests and interview or the sample size was too narrow to consider it a valid observation for the generalization. Another issue of these studies are that mostly the studies on recruitment and selection have addressed the researched issue separately while as the both are totally interrelated which could have given better results if analyzed simultaneously. Furthermore, most of the studies have been conducted in developed especially among English speaking countries; this has also become a main issue for generalizing the findings of these studies in the context of least developing countries in the world, because their socioeconomic and governance setup is entirely different. Moreover, there are almost negligible studies that have focused the issue of recruitment and selection comprehensively by covering maximum relevant dimensions of the field. Therefore, it is necessary that the researches needs to focus the issue of recruitment and selection comprehensively in these countries particularly focusing on the public sector institutions by taking a reasonable sample from the key sectors of the country. This will not only help to have a broader and more practical scenario based understanding about the recruitment and selection but also this will be useful to know how valid are the existing studied findings in the English non speaking and under developing countries. Therefore, we are fully focusing on this comprehensive study as concluded in this study.

\section{References}

Bagilhole, B. and Goode, J. (2001), "The contradiction of the myth of individual merit, and the reality of a patriarchal support system in academic careers; a feminist investigation", The European Journal of Women's Studies, Vol. 8 No. 2, pp. 161-80.

Ben chop, Y. and Broun's, M. (2003), “Crumbling ivory towers: academic organizing and its gender effects”, Gender, Work and Organization, Vol. 10 No. 2, pp. 194-212.

Bossaert, D., Demmke, C., 2003. Civil Services in the Accession States. EIPA, Maastricht.

Breaugh, J. A. (2008). Employee recruitment: Current knowledge and important areas for 
future research. Human Resource Management Review,18(3), 103-118.

Broun's, M. (2000), “The gendered nature of assessment procedures in scientific research funding: the Dutch case", Higher Education in Europe, Vol. 25, pp. 193-201.

Catano.V.M., Wiesner.W.H., Hackett.R.D.,\& Methot.L.(2004). Recruitment and selection in Canada. Nelson Education Ltd.

Chan, D., Schmitt, N., Jennings, D., Clause, C. S., \& Delbridge, K. (1998).Applicant perceptions of test fairness: Integrating justice and self-serving bias perspectives. International Journal of Selection and Assessment, 6, 232-239.

Chan, D., Schmitt, N., Jennings, D., Clause, C. S., \& Delbridge, K. (1998).Applicant perceptions of test fairness: Integrating justice and self-serving bias perspectives. International Journal of Selection and Assessment, 6, 232-239.

Cole, M., Field, H. and Giles, W. (2004), "Interaction of recruiter and applicant gender in resume evaluation: a field study", Sex Roles, Vol. 51 Nos 9/10, pp. 597-608.

Compton, R. L., Morrissey, W. J., Nankervis, A. R., \& Morrissey, B. (2009). Effective recruitment and selection practices. $\mathrm{CCH}$ Australia Limited.

Cropanzana, R., Bowen, D. E., \& Gilliland, S. W. (2007). The management of organizational justice. The Academy of Management Perspectives, 34-48.

Doherty, L., \& Manfredi, S. (2006). Women's progression to senior positions in English universities. Employee Relations, 28(6), 553-572.

Drory.A,Gadot.E.V. (2010). Organizational politics and human resource management: A typology and the Israeli experience. Human Resource Management Review, 20, 194-202

Gaber, J., \& Gaber, S. L. (2010). Using face validity to recognize empirical community observations. Evaluation and program planning, 33(2), 138-146.

Gilliland, S. W. (1993). The perceived fairness of selection systems: an organizational justice perspective. Academy of Management Review, 18, 694-734.

Gilliland, S. W., \& Steiner, D. D. (1999). Applicant reactions to interviews: Procedural and interactional justice of recent interview technology. In R. W. Eder \& M. M. Harris (Eds.), The employment interview: Theory, research, and practice (pp. 69-82). Thousand Oaks, CA: Sage

Gajduschek, G. (2007). Politicisation, professionalisation, or both? Hungary's civil service system. Communist and Post-Communist Studies, 40(3), 343-362.

Gau, Jacinta., M.(2011). The Convergent and Discriminant Validity of Procedural Justice and Police Legitimacy: An Empirical Test of Core Theoretical Propositions. Journal of Criminal Justice, 39, 489-498

Górecki, M. A., \& Kukołowicz, P. (2014). Gender quotas, candidate background and the election of women: A paradox of gender quotas in open-list proportional representation systems. Electoral Studies, 36, 65-80. 
Hardesty, D. M., \& Bearden, W. O. (2004). The use of expert judges in scale development: Implications for improving face validity of measures of unobservable constructs. Journal of Business Research, 57(2), 98-107.

Harris, L. (2000). Procedural justice and perceptions of fairness in selection practice. International Journal of Selection and Assessment, 8(3), 148-157.

Harris, H. (2002), “Think international manager, think male: why are women not selected for International assignments?" . Thunderbird International Business Review, Vol. 44 No. 2, pp. 175-203.

Hausknecht, J. P., Day, D. V., \& Thomas, S. C. (2004). Applicant Reactions to Selection Procedures: An Updated Model and Meta-Analysis. Personnel Psychology, 57(3), 639-683.

Huber, John D., and Nolan McCarty. (2004). Bureaucratic Capacity, Delegation, and Political Reform. American Political Science Review 98 (3): 481-94.

Husu, L. (2000), "Gender discrimination in the promised land of gender equality", Higher Education in Europe, Vol. 25 No. 2, pp. 221-8.

Hsu, Y. R., \& Leat, M. (2000). A study of HRM and recruitment and selection policies and practices in Taiwan. International Journal of Human Resource Management, 11(2), 413-435.

Khurana, R. (2002), Searching for a Corporate Savior. The Irrational Quest for Charismatic CEO's, Princeton University Press, Princeton, NJ. Liu, S. (2013). A few good women at the top: The China case. Business Horizons, 56(4), 483-490.

Krause, G. A., Lewis, D. E., \& Douglas, J. W. (2006). Political appointments, civil service systems, and bureaucratic competence: Organizational balancing and executive branch revenue forecasts in the American states. American Journal of Political Science, 50(3), 770-787.

Kaufman, Herbert. (1965). The Growth of the Federal Personnel System. In The Federal Government Service, eds. Wallace S. Sayre. Englewood Cliffs, NJ: Prentice-Hall, Inc., 7-69.

Kerlinger, F. (1986). Foundations of behavioral research (third ed.). New York, NY: Holt,

Rinehart and Winston.

Krinitcyna, Z. V., \& Menshikova, E. V. (2015). Discrimination Issues in the Process of Personnel Selection. Procedia-Social and Behavioral Sciences, 166, 12-17.

Kusterer (2014). Gender equality and liberal individualism:Acritical reading of economist discourse in Sweden.Scandinavian Journal of Management, Vol.30,pp.306-316

Lee, R., \& Renzetti, C. (1990). The problems of researching sensitive topics. American Behavioral Scientist, 33, 510-528.

Lewis, P. (2003). New China-old ways?: A case study of the prospects for implementing human resource management practices in a Chinese state-owned enterprise. Employee Relations, 25(1), 42-60. 
Linghag, S., \& Regnö, K. (2009). What is Gender in Organizations?.

Liu, S. (2013). A few good women at the top: The China case. Business Horizons, 56(4), 483-490.

Lievens, F., Buyse, T., \& Sackett, P. R. (2005). The operational validity of a video-based

situational judgment test for medical college admissions: Illustrating the importance of matching predictor and criterion construct domains. Journal of Applied Psychology, 90, 442-452. doi: 10.1037/0021-9010.90.3.442

Marshall, M. G., \& Ramsey, D. (1999). Gender empowerment and the willingness of states to use force. Unpublished research paper, Center for Systemic Peace. Available at http://www. members. aol. com/CSPmgm.

McNamee, S.J. andMiller, R.K.J. (2004), TheMeritocracy Myth, Rowman\&Littlefield, Lanham,MD.

Moser, A. (2007). Gender and indicators: overview report. Bridge, Institute of Development Studies.

Nabi, G., Wei, S., Husheng, X., Shabbir, M., Altaf, M., \& Zhao, S. (2014). Effective Recruitment and Selection Procedures: an Analytical Study Based on Public Sector Universities of Pakistan. Public Policy and Administration Research, 4(10), 12-20.

Nabi, G., Wei, S., Shabbir, M., Altaf, M., (2014). Procedural justice, organizational \& State Politics: the real challenge for the right selection in public sector institution of Pakistan. International Journal of Business Management and Research 41(02), 1193-1201

Nabi G., Wei, S., Zhao, S., \& Shabbir,M. (2015). Selection Procedures, Face Validity and Fairness in Higher Academic Institutions of Pakistan. Journal of Management Research, 7(1).

Nabi G., Wei, S. Female Stereotype of Male Dominancy: a study based on Cabinets headed by Female as Chief Executive of the Country. Global Journal of Management and Business Research.XIV (XI)

Newfields, T. (2002). Challenging the notion of face validity. JALT Testing and Evaluation SIG Newsletter, 6(3), 19.

Phillips, A. (1995). The politics of presence. Oxford: Clarendon Press

Ployhart, R. E. (2006). Staffing in the 21st century: New challenges and strategic opportunities. Journal of Management, 32(6), 868-897.

Ryan, A.M. and Ployhart, R.E. (2000) Applicants' perceptions of selection procedures and decisions: A critical review and agenda for the future. Journal of Management, 26, 565-606.

Saks, A.M. (2005). The impracticality of recruitment research. In A. Evers N. Anderson \& O. Voskuijl (Eds.), Handbook of personnel selection (pp. 47-72). Malden, MA:Blackwell.

Sealy, R., Doldor, E. and Vinnicombe, S. (2009a), Increasing Diversity on Public and Private 
Sector Boards - Part 2. What is Being Done to Improve Diversity on Boards and How Effective is This?, Government Equalities Office, London.

Sealy, R. (2010). Changing perceptions of meritocracy in senior women's careers. Gender in Management: An International Journal, 25(3), 184-197.

Schneider, B. R. (1992). Politics within the State: elite bureaucrats and industrial policy in authoritarian Brazil. University of Pittsburgh Pre.

Simon, Herbert A., Victor A. Thompson, and Donald W. Smithburg. [1950] 1991. Public Administration. New Brunswick, NJ: Transaction Publishers.

Son Hing, L.S., Bobocel, D.R. and Zanna, M.P. (2002), "Meritocracy and opposition to affirmative action: making concessions in the face of discrimination", Journal of Personality \& Social Psychology, Vol. 83 No. 3, pp. 493-509.

Schinkel, S., Van Dierendonck, D., \& Anderson, N. (2004). The impact of selection encounters on applicants: An experimental study into feedback effects after a negative selection decision. International Journal of Selection and Assessment, 12(1-2), 197-205.

Suleiman, Ezra. 2003.DismantlingDemocratic States.Princeton: Princeton University Press

Syed, J., Özbilgin, M., Torunoglu, D., \& Ali, F. (2009, April). Rescuing gender equality from the false dichotomies of secularism versus shariah in Muslim majority countries. In Women's Studies International Forum (Vol. 32, No. 2, pp. 67-79). Pergamon.

Teigen, M. (2000). The a \$rmative action controversy. NORA, 2(8), 63$\} 77$.

Teigen, M. (2002). The suitable few: managerial recruitment practices in the Norwegian state bureaucracy. Scandinavian Journal of Management, 18(2), 197-215.

Tucker, P. D. and Pounder D.G. (2010). Supervision and Personnel Administration. Leadership and Management, pp. 839-845

Snyder, Suzanne K., and Barry R.Weingast. 2000. "The American System of Shared Powers: The President, Congress, and the NLRB." Journal of Law, Economics, and Organization, 16(October):269-305.

Steinpreis, R., Anders, K. and Ritzke, D. (1999), "The impact of gender on the review of the curricula vitae of job applicants and tenure applicants: a national empirical study",

Sex Roles, Vol. 41 Nos 7/8, pp. 509-28

Taylor, S. (2006). Acquaintance, meritocracy and critical realism: Researching recruitment and selection processes in smaller and growth organizations. Human Resource Management Review, 16(4), 478-489.

Taylor, S. (2007). Acquaintance, meritocracy and critical realism: Researching recruitment and selection processes in smaller and growth organizations. Human Resource Management Review. 16, 478-489 


\section{Macrothink}

International Journal of Human Resource Studies

ISSN 2162-3058

2015, Vol. 5, No. 2

Truxillo, D. M., Steiner, D. D., \& Gilliland, S. W. (2004). The importance of organizational justice in personnel selection: Defining when selection fairness really matters. International Journal of Selection and Assessment, 12(1-2), 39-53.

Van Balen, B. (2001), Vrouwen in de Wetenschappelijke Arena. Sociale sluiting in de universiteit (Women in the Academic Arena. Social Closure Inside the University), Het Spinhuis, Amsterdam.

Van den Brink, M., Brouns, M., \& Waslander, S. (2006). Does excellence have a gender? A national research study on recruitment and selection procedures for professorial appointments in The Netherlands. Employee Relations, 28(6), 523-539.

Van den Brink, M., \& Ben chop, Y. (2012). Gender practices in the construction of academic excellence: Sheep with five legs. Organization,19(4), 507-524.

Van Vianen, A. E., Taris, R., Scholten, E., \& Schinkel, S. (2004). Perceived fairness in personnel selection: Determinants and outcomes in different stages of the assessment procedure. International Journal of Selection and Assessment, 12(1-2), 149-159.

Vigoda, E. (2000). Organizational politics, job attitudes, and work outcomes: Exploration and implications for the public sector. Journal of vocational Behavior, 57(3), 326-347.

Vigoda, E. (2003). Developments in organizational politics: How political dynamics after employee performance in modern work sites. Cheltenham:Edward Elgar.

Vigoda-Gadot, Eran, and Danit Kapun. 2005. Perceptions of politics and performance in public and private organizations: A test of one model across two sectors. Policy and Politics 33 (2): 251-76.

Vigoda-Gadot, E. (2007). Citizens' perceptions of politics and ethics in public administration: A five-year national study of their relationship to satisfaction with services, trust in governance, and voice orientations. Journal of Public Administration Research and Theory, 17(2), 285-305.

Schueller-Weidekamm, C., \& Kautzky-Willer, A. (2012). Challenges of Work-Life Balance for Women Physicians/Mothers Working in Leadership Positions. Gender medicine, 9(4), 244-250.

Ziegler, Beatrice (2001). 'Some remarks on gender equality in higher education in Switzerland'. International Journal of Sociology and Social Policy 21/1-2: 44-49. 